\title{
Education for Sustainable Develoment (ESD) - Pancasila di Desa Towangsan: Paradigma Pembangunan yang Berkelanjutan
}

\author{
Sindung Tjahyadi, Andhika Djalu Sembada, \\ Hastangka ${ }^{*}$, dan Yesika Theresia Sinaga \\ Pusat Studi Pancasila, Universitas Gadjah Mada, Yogyakarta \\ *hastangka@gmail.com \\ Submisi: 08 November 2017; Penerimaan: 22 Januari 2019
}

Kata Kunci: ESD; pembangunan yang berkelanjutan; Pancasila

Keywords: ESD;

Pancasila; sustainable development.
ABSTRAK Desa Towangsan, Gantiwarno, Kabupaten Klaten, Jawa Tengah memiliki potensi modal sosial, kultural, dan ekonomi lokal yang dapat menjadi model dan aplikasi untuk secara terus menerus mempertahankan nilai-nilai lokalitas dan nilai-nilai pembangunan yang berkelanjutan berdasarkan jati diri dan kepribadian bangsa Indonesia, yaitu Pancasila. Pancasila menjadi dasar moral dan dasar nilai dalam merumuskan kebijakan pembangunan desa di Desa Towangsan Gantiwarno, Kabupaten Klaten, Jawa Tengah. Kegiatan pengabdian kepada masyarakat dengan kerangka implementasi ESD dalam masyarakat yang dilaksanakan oleh Pusat Studi Pancasila UGM bertujuan untuk mendesain dan merumuskan Pusat Inovasi dan Pengembangan Pendidikan untuk Pembangunan yang berkelanjutan (ESD) Indonesia berbasis komunitas dan berdasarkan nilai-nilai Pancasila. Pusat Inovasi dan Pengembangan Pendidikan untuk Pembangunan yang berkelanjutan ini dibentuk untuk memberikan dasar pijakan dan komitmen bagi komunitas di desa agar senantiasa berupaya secara sadar dan terus menerus untuk mengaktualisasikan nilai-nilai pembangunan yang berkelanjutan sesuai dengan bidang yang digeluti, seperti komunitas Sanggar Lare Mentes berbasis kebudayaan dan karang taruna berbasis pembangunan yang berkelanjutan. Hasil yang dicapai dalam kegiatan ini adalah terbentuknya Pusat Inovasi dan Pengembangan ESD berbasis komunitas di Desa Towangsan Gantiwarno, munculnya kesadaran masyarakat akan pentingnya pembangunan yang berkelanjutan, dan pendokumentasian profil Desa Towangsan yang didasarkan pada nilai-nilai Pancasila. Pelaksanaan kegiatan Implementasi ESD-Pancasila juga membawa dampak positif di Towangsan karena telah mengubah pola pikir dan cara berpikir masyarakat dari yang ekslusif menjadi inklusif.

ABSTRACT The village of Towangsan, Gantiwarno, Klaten district, Central Java has the potential of social, cultural and local economic capital that can serve as a model and application to continually maintain the values of locality, sustainable development values based on the identity and personality of the Indonesian nation namely Pancasila. Pancasila became the basic moral and basic values in formulating village development policy in Towangsan Gantiwarno village, Klaten regency, Central Java. Community service activities with ESD implementation framework in society implemented by UGM Pancasila Study Center is to design and formulate Indonesia-based Center for Innovation and Education for Sustainable Development (ESD) based on Pancasila values. The Center for 
Innovation and Development of Education for Sustainable Development is to provide the foundation and commitment of the village community in order to work consciously and continuously actualize the values of sustainable development in accordance with the areas that are involved such as Lare mentes community based culture community, and Karang Taruna based sustainable development. The results achieved in this activity are the establishment of a community-based ESD Innovation and Development Center in Towangsan Gantiwarno Village, community awareness of the importance of sustainable development, and the documentation of Towangsan village profiles based on Pancasila values. Implementation of ESDPancasila Implementation also has a positive impact in Towangsan because it has changed the mindset and way of thinking of the exclusive from the exclusive.

\section{PENDAHULUAN}

\subsection{Pengertian ESD}

Pendidikan untuk Pembangunan yang Berkelanjutan (Education for Sustainable Development-ESD) bermakna sebagai upaya untuk memberdayakan masyarakat dalam mengubah cara berpikir dan bekerja dalam menghadapi masa depan yang lebih berkelanjutan $^{1}$. Pengertian ini didasarkan pada suatu kondisi dunia yang memiliki jumlah penduduk mencapai 7 miliar orang dan semakin terbatasnya sumber daya alam untuk dapat mencukupi kebutuhan manusia yang "tidak terbatas". Sebagai individu dan masyarakat, manusia harus memahami cara hidup yang berkelanjutan. Kajian yang dilakukan oleh Segara menunjukkan bahwa masalah dunia yang semakin kompleks sekarang ini tidak bisa hanya didekati dari satu sudut pandang saja. Menurutnya, persoalan yang terjadi pada suatu negara akan berdampak pada sistem global yang ada sehingga masalah yang terjadi di suatu negara perlu dipecahkan secara bersama-sama (Segara, 2015).

Tindakan yang bertanggung jawab perlu diambill untuk memberi pemahaman kepada semua orang bahwa setiap tindakan/perbuatan yang dilakukan hari ini akan berdampak pada masa depan kehidupan manusia dan planet bumi. Definisi lain terkait ESD juga dikembangkan oleh UNESCO sebagai berikut.

"Education for Sustainable Development (ESD) is a learning process (or approach to teaching) based on the ideals and principles that underlie sustainability and is concerned with all levels and types of learning to provide quality education and foster sustainable human development learning to know, learning to be, learning to live together, learning to do and learning to transform oneself and society."2

Pengertian di atas memberikan pesan bahwa konsep pendidikan untuk pembangunan yang berkelanjutan adalah suatu proses belajar yang dilakukan secara terus menerus dan secara sadar untuk membangun masyarakat dan merawat bumi dengan baik. Pendidikan untuk pembangunan yang berkelanjutan merupakan salah satu bentuk upaya untuk mempercepat tujuan pembangunan yang berkelanjutan dan agenda MDGs (Byun, W.J., Leicht, A., Heiss, J, 2018). Pendidikan pembangunan yang berkelanjutan diarahkan untuk pembangunan yang berwawasan lingkungan dan terbentuknya green globe (bumi yang hijau dan lestari) (Amyyana, Paristiowati, dan Kurniadewi, 2017).

\footnotetext{
${ }^{1}$ http://en.unesco.org/themes/education-sustainable-development, diakses 31 Mei 2017 12:22. ${ }^{2}$ http://www.unescobkk.org/education/esd-unit/definition-of-esd/, dikases, 31 Mei 2017 12:34.
} 


\subsection{Ruang Lingkup ESD}

Ruang lingkup pendidikan untuk pembangunan yang berkelanjutan ialah aspek lingkungan dalam konteks lingkungan sosial, politik, ekonomi, budaya, dan persoalan global yang dihadapi berdasarkan aspek isi atau materi yang hendak ditawarkan. Metode yang dikembangkan dalam pengimplementasian pendidikan untuk pembangunan yang berkelanjutan ini, antara lain, interdisipliner (lintas disiplin), memfokuskan pada pembelajar (masyarakat dan individu), didasarkan pada proses pencarian dan pengalaman, serta menekankan kemitraan dan berpikir sistematis. Penerapan yang dilakukan dalam ESD ini lebih fokus pada tindakan warga masyarakat dan nilai yang dibangun, yakni kesadaran dan kepedulian terhadap lingkungan di sekitarnya ${ }^{3}$. Dalam Issues and Trends in Education for Sustainable Development dijelaskan bahwa pelaksanaan ESD diarahkan pada lima agenda prioritas, yakni memperkuat kebijakan, mentransformasikan nilai-nilai pembelajaran dan pelatihan di bidang lingkungan, membangun kapasitas pendidik dan trainer, memberdayakan dan memobilisasi pemuda, dan melakukan percepatan agenda pembangunan yang berkelanjutan di tingkat lokal (Byun, W.J., Leicht, A., dan Heiss, J, 2018).

\subsection{Perkembangan Implementasi ESD}

Implementasi ESD dalam berbagai perkembangannya dibagi menjadi beberapa kategori. Pertama, implementasi dalam bidang pendidikan formal. Penerapan ESD dalam bidang ini ditujukan pada institusi pendidikan, seperti sekolah dan perguruan tinggi untuk melakukan edukasi kepada para peserta didik dan mahasiswa terkait dengan persoalan dan tantangan pendidikan untuk pembangunan yang berkelanjutan. Studi yang telah dilakukan oleh Zaenuri, Utomo, dan Juul menunjukkan model implementasi ESD di sekolah, khususnya pada bidang pendidikan lingkungan di sekolah dasar melalui studi kasus di Sekolah Dasar Negeri 1 di Kota Banda Aceh. Implementasi ESD yang diterapkan ialah membangun kesadaran dan pembiasaan sejak dini tentang pentingnya kesadaran lingkungan yang berkelanjutan dengan menanamkan nilai-nilai kepada peserta didik untuk hidup bersih, sehat, dan berkelanjutan di sekolah mereka (Zaenuri, Utomo, dan Juul, 2017).

Secara umum, pendidikan untuk pembangunan yang berkelanjutan (ESD) diberikan dan disinergikan dalam institusi pendidikan, khususnya sekolah dan perguruan tinggi dengan menginterasikannya pada pembelajaran di kelas meskipun tidak tersirat secara langsung dalam struktur kurikulum yang ada. Pendidikan demi pembangunan berkelanjutan dapat juga diberikan secara nonformal kepada masyarakat umum sebagai upaya mewujudkan pelestarian lingkungan sekitar, misalnya dengan memberikan pemahaman melalui kegiatan penyuluhan (Marthaliakirana, Irawati, dan Rohman, 2018).

Kedua, implementasi dalam bidang komunitas. Implementasi ini diarahkan untuk melibatkan partisipasi masyarakat dan komunitas dalam upaya pemberdayaan dan sosialisasi kepada masyarakat dan komunitasnya tentang pentingnya membangun kesadaran bersama untuk mengatasi persoalan pembangunan yang berkelanjutan yang dihadapi oleh umat manusia. Ketiga, implementasi ESD di bidang pelatihan dan penelitian. Implementasi ini diarahkan untuk merumuskan dan mendesain produk yang mampu mendukung umat manusia

${ }^{3}$ http://www.desd.sustain-future.org/ESD_Emerging_Paradigm.pdf, diakses 31 Mei 2017 13:05. 
untuk mengatasi persoalan pembangunan, seperti pelatihan dan pengembangan konstruksi bangunan yang lebih berkelanjutan dan ramah lingkungan serta efisien dengan energi ${ }^{4}$.

\section{METODE}

Metode yang digunakan untuk merealisasikan program pengabdian masyarakat hibah implementasi pendidikan untuk pembangunan yang berkelanjutan dalam masyarakat dengan judul "Mendesain Pusat Inovasi Pengembangan Pendidikan untuk Pembangunan yang Berkelanjutan (ESD) Indonesia Berbasis Komunitas berdasarkan Nilai-nilai Pancasila di Desa Towangsan, Ganti Warno, Klaten Jawa Tengah" adalah dengan melaksanakan beberapa kegiatan, antara lain, penyusunan proposal dan penyempurnaannya serta pelaksanakan kegiatan yang meliputi (1) koordinasi internal; (2) koordinasi eksternal dengan mitra-mitra kerja; (3) studi kepustakaan, terutama kepustakaan tentang ESD dan Pancasila; (4) sosialisasi; (5) Focus Group Discussion; (6) pelatihan ESD-Pancasila; (7) workshop ESD berbasis nilainilai Pancasila; (8) festival ESD; dan (9) pembuatan desain/logo Pusat Inovasi dan Pengembangan ESD-Pancasila Berbasis Komunitas di Desa Towangsan Gantiwarno.

\section{HASIL DAN PEMBAHASAN}

\subsection{Profill Desa Towangsan Gantiwarno, Kabupaten Klaten}

Desa Towangsan terletak di Kecamatan Gantiwarno, Kabupaten Klaten, Provinsi Jawa Tengah. Desa Towangsan memilik enam dusun, yaitu Dusun Titang, Dusun Tosadu, Dusun Turen, Dusun Tangkisan, Dusun Sembungan, dan Dusun Pundung. Desa Towangsan terdiri atas tujuh RW dan delapan belas RT.

Secara umum jumlah penduduk Desa Towangsan per 31 Desember 2017 adalah sekitar 2.425 jiwa (1.213 orang laki-laki dan 1.212 orang perempuan). Mayoritas penduduk Desa Towangsan beragama Islam (2.064 jiwa). Adapun masyarakat yang memeluk agama Katholik sebanyak 346 jiwa dan Kristen sebanyak 15 jiwa $^{5}$.

Mata pencaharian utama penduduk Desa Towangsan adalah sebagai petani. Kurang lebih $75 \%$ luas wilayah Desa Towangsan adalah sawah dan ladang. Data statistik Desa Towangsan menunjukkan bahwa luas wilayah Desa Towangsan adalah 147.4070 ha yang terbagi menjadi 106.6860 ha area persawahan; 32.9295 ha area pekarangan, dan 7.7915 ha lain-lain ${ }^{6}$. Hampir 95\% penduduk Desa Towangsan adalah suku Jawa (Diolah dari BPS Kabupaten Klaten). Hal itu membuat adat istiadat dan ciri masyarakat cenderung seperti orang Jawa pada umumnya. Kegiatan-kegiatan yang ada di desa juga mencakup kegiatan keagamaan (mayoritas Islam) dan kegiatan kebudayaan (merti desa dan wayang kulit). Hubungan antarumat beragama terjalin dengan sangat baik, khususnya antara umat Islam dan Kristen. Menurut warga setempat, belum ada kasus yang menyebabkan perselisihan antara kedua agama tersebut (Wawancara dengan Pak Lurah, 26 Oktober 2017). Selain itu, Desa Towangsan juga memiliki kegiatan rutin, yakni bersih desa (merti desa). Selain membersihkan desa dari sampah dan kotoran, kegiatan rutin ini menjadi wadah dan sarana bagi masyarakat untuk beraktivitas, berkreativitas, dan melakukan kegiatan sosial melalui aksi gotong royong.

\footnotetext{
${ }^{4}$ http://www.unescobkk.org/education/esd-unit/good-practice/, diakses 31 Mei 2017 13:21.

${ }^{5}$ https://web.desatowangsan.com/tentang-desa/, diakses 30 Agustus 2017, 13:59.

${ }^{6}$ https://web.desatowangsan.com/tentang-desa/, diakses 30 Agustus 2017, 13:59.
} 
Desa Towangsan sampai saat ini telah memiliki lima instansi/organisasi yang terstruktur, yakni:

a. Pemerintah Kabupaten Klaten, Kecamatan Gantiwarno, Desa Towangsan.

b. Babinsa Towangsan (Militer)

c. Badan Permusyawaratan Desa (BPD)

d. Pemberdayaan dan Kesejahteraan Keluarga (PKK)

e. Karang Taruna Sekarwono

Organisasi tersebut menjadi bagian penting dalam upaya pemberian pelayanan dan ruang dialog yang memadai bagi warga masyarakat dan untuk dapat memberdayakan masyarakat ke arah yang lebih baik.

\subsection{Potensi Desa Towangsan}

Desa Towangsan memiliki kelengkapan infrastruktur berupa jembatan, jalan besar dan jalan kecil, irigasi, gapura desa, balai desa, kantor desa, perpustakaan desa, sekolah dasar, lumbung desa, bank sampah, pos kamling, masjid, sanggar, pertokoan, fotokopi, dan lapangan. Secara keseluruhan, infrastruktur tersebut sudah cukup, namun belum dapat mendukung terwujudnya pendidikan untuk pembangunan yang berkelanjutan.

\subsection{Tantangan di Desa Towangan}

Berikut ini tantangan pembangunan yang berkelanjutan di Desa Towangsan

\subsubsection{Tantangan Lingkungan di Desa Towangan}

Desa Towangsan secara umum memiliki infrastruktur yang cukup memadai, seperti fasilitas pemerintahan, sekolah, perpustakaan desa, lumbung desa dan bak sampah. Akan tetapi, ada beberapa hal yang masih perlu dibenahi guna mendukung pemeliharaan lingkungan yang baik dan nyaman bagi masyarakat. Berdasarkan observasi yang dilakukan oleh tim penulis bersama kelompok karang taruna pada periode Juni-September 2018 diketahui bahwa secara umum kesadaran masyarakat Desa Towangsan untuk membuang sampah di tempatnya dan juga mengalokasikan sampah organik dan nonorganik masih minim. Di sepanjang jalan-jalan kecil dan parit/selokan di Desa Towangsan masih sering ditemukan sampah.

Kajian Sulistiyani dan Wulandari menunjukkan bahwa salah satu masalah dalam pembangunan yang berkelanjutan ialah persoalan sampah (Sullistiyani dan Wulandari, 2017). Setiap manusia dan setiap rumah tangga di suatu desa memproduksi sampah, baik sampah organik maupun nonorganik. Penggunaan "bank sampah" juga belum efektif karena manajemen pengelolaannya yang belum berkelanjutan. Bank sampah merupakan tempat untuk mengolah sampah-sampah yang diambil dari warga. Sampah-sampah tersebut diolah menjadi bahan-bahan yang bermanfaat bagi masyarakat. Akan tetapi, dalam praktiknya terkadang pengangkutan sampah tidak dilakukan secara menyeluruh dan belum secara rutin dilakukan.

Kondisi jalan-jalan di Towangsan sudah tergolong baik. Sebagian jalan dan jembatan sudah permanen karena terbuat dari beton dan aspal, tetapi belum ada rambu-rambu jalan, petunjuk arah, dan penerangan jalan yang cukup. Hal-hal tersebut menjadi hambatan dan 
ancaman terwujudnya pembangunan yang berkelanjutan dari tiga aspek, yaitu ekonomi, sosial-budaya, dan lingkungan.

\subsubsection{Tantangan Ekonomi di Desa Towangan}

Mata pencaharian utama masyarakat Desa Towangsan adalah sebagai petani. Berdasarkan data statistik Desa Towangsan diketahui bahwa kurang lebih hampir $75 \%$ kawasan desa adalah sawah dan ladang (sekitar 106.6860 ha dari total luas wilayah sebesar 147.4070 ha adalah area persawahan dan 32.9295 ha adalah area pekarangan). ${ }^{7}$ Sumber irigasi, pengolahan hasil pertanian, dan penanggulangan limbah menjadi masalah yang berkaitan dengan mata pencaharian pokok warga Towangsan.

Belum adanya sumber mata air dan irigasi yang permanen menghambat masyarakat untuk meningkatkan kualitas hasil pertaniannya, khususnya padi. Selain itu, hambatan lain yang mengancam hasil produksi saat musim kering sehingga perekonomian desa menjadi kurang stabil adalah kurangnya alat-alat pendukung, seperti lumbung desa yang hanya ada satu sehingga tidak bisa mengakomodasi banyaknya hasil pertanian pada musim panen serta peralatan yang masih belum terbarukan (mesin penggiling padi yang masih kuno). Secara umum tingkat kesejahteraan masyarakat di Desa Towangsan cukup baik.

\subsubsection{Tantangan Sosial-Budlaya di Desa Towangan}

Desa Towangsan memiliki Karang Taruna Sekarwono yang dibentuk pada Januari 2017. Organisasi ini menjadi organisasi termuda yang diprakarsai dan dijalankan oleh pemuda Desa Towangsan yang sebagian sudah bekerja, kuliah, dan masih sekolah. Hal ini menjadi salah satu kemajuan yang menunjukkan bahwa Desa Towangsan memiliki perhatian terhadap generasi muda sebagai fokus utama pendidikan untuk pembangunan desa yang berkelanjutan.

Usia Karang Taruna Sekarwono yang masih baru secara kelembagaan membuat organisasi ini belum memiliki program kerja, rancangan anggaran dasar dan anggaran rumah tangga (AD/ART) yang jelas dan teratur. Oleh karena itu, diperlukan penyusunan ulang tata kelola organisasi yang matang. Anggota Karang Taruna juga masih bingung dengan misi dan visi mereka. Hal itu disebabkan kurangnya minat dan komitmen secara utuh dari anggota. Para anggota karang taruna terkadang sibuk dengan aktivitasnya masing-masing. Secara finansial, karang taruna ini didukung oleh Kelurahan Desa Towangsan, namun pendampingan masih sangat kurang.

Beberapa kebiasaan-kebiasaan buruk juga masih ditemui di tengah kehidupan masyarakat Desa Towangsan, yakni kebiasaan mabuk-mabukan, judi yang belum dapat ditertibkan, sikap warga yang masih individual, kurangnya kesadaran akan budaya (mempertahankan adat dan kebiasaan, khususnya oleh anak muda), kurangnya kreativitas dan minimnya prestasi, khususnya anak-anak muda. Salah satu faktor yang menyebabkan hal tersebut adalah kurang meratanya tingkat pendidikan masyarakat. Di Desa Towangsan hanya terdapat 2 TK; 1 Sekolah Dasar, dan 1 Sekolah Menengah Pertama (SMP). Adapun SMA berada di wilayah desa lain atau kecamatan lain.

\footnotetext{
${ }^{7}$ https://web.desatowangsan.com/tentang-desa/, diakses 30 Agustus 2017, 13:59.
} 
Penghambat kreativitas pemuda karang taruna yang lain adalah keterampilan berorganisasi yang minim Selain itu, masyarakat masih tidak acuh terhadap program-program karang taruna sehingga partisipasi dan respons yang diharapkan masih sangat kurang. Hal ini menyebabkan semangat dan keinginan berkarya para pemuda Desa Towangsan semakin berkurang.

Di Desa Towangsan ada satu sanggar yang kegiatannya berfokus pada pendampingan pemuda dan anak-anak. Sanggar tersebut bernama Lare Mentes. Sanggar ini terpisah dari karang taruna, namun pemuda-pemuda yang tergabung dalam sanggar tersebut didominasi oleh pemuda Desa Towangsan. Sanggar ini sudah berdiri kurang lebih sepuluh tahun dan telah menjalankan banyak program, baik dari luar maupun dari dalam Desa Towangsan. Sampai sekarang, sanggar Lare Mentes merupakan organisasi terbuka yang keanggotaannya tanpa batas. Sanggar ini bertujuan melestarikan dan merawat kesenian. Salah satu kegiatan yang diselenggarakan oleh Sanggar Lare Mentes dan Karang Taruna Sekarwono adalah Festival Anak sebagai bagian dari perayaan Hari Anak Nasional 2017. Kegiatan ini melibatkan seluruh anak-anak di Desa Towangsan.

Festival ini diselenggarakan dalam rangka memperingati Hari Anak Nasional. Beberapa kegiatan yang dilaksanakan dalam festival ini adalah lomba menggambar tentang desa, lomba tari tradisional, pengenalan permainan tradisional, dan outbound untuk mengajak anak-anak mengenal desanya. Outbound ini diselingi dengan berbagai macam kuis dan aneka permainan, seperti memindahkan air dalam botol serta permainan kekompakkan dan kerja sama dalam tim.

\subsection{Pencapaian Hasil Education for Sustainable Development (ESD) di Desa Towangsan}

\subsubsection{Sosialisasi Education for Sustainable Development (ESD) di Desa Towangsan}

Konsep sosialisasi ESD dalam masyarakat ini bertujuan untuk memberikan pengetahuan awal dan informasi tentang pengertian, ruang lingkup kerja, dan aspek-aspek yang perlu dilakukan untuk melakukan kegiatan yang berpijak pada pembangunan yang berkelanjutan. Prinsip pembangunan yang berkelanjutan ditawarkan sebagai upaya untuk membangun masyarakat yang mampu mengelola sumber kehidupan yang ada di sekitarnya, yaitu air, tanah, dan lingkungan alam tanpa mengabaikan masa depan generasi selanjutnya serta kelestarian lingkungan alam. Konsep dan paradigma pembangunan yang mengabaikan prinsip dan nilai-nilai keberlanjutan akan membawa dampak buruk bagi keberlangsungan masyarakat atau desa yang ditempati.

\subsubsection{Focus Group Discussion (FGD) tentang Pembangunan yang Berkelanjutan di Desa Towangsan}

Kegiatan FGD bagi para perangkat desa telah menghasilkan materi dan masukan yang terkait dengan persoalan-persoalan ESD yang dihadapi di desa melalui tiga kerangka dasar, yaitu lingkungan, ekonomi, dan sosial-budaya. Masyarakat dihadapkan pada pilihan yang sulit ketika harus berhadapan dengan kondisi alam dan lingkungan. Ketika musim kemarau tiba dan hasil panen gagal, misalnya, masyarakat kehilangan mata pencaharian dan penghasilan dari hasil pertanian. Masyarakat di Desa Towangsan menyadari akan kondisi desa yang semakin buruk akibat lingkungan yang kurang mendukung. Akan tetapi, generasi 
muda dan para perangkat desa terkadang belum semuanya sepakat untuk membangun desa atau memajukan desa. Oleh karena itu, pendidikan untuk pembangunan yang berkelanjutan menjadi bagian terpenting dalam proses penguatan desa ke arah yang lebih baik.

Kegiatan FGD dengan perangkat desa di atas dipimpin oleh Kepala Desa Towangsan dan didampingi oleh Tim ESD Pancasila UGM. Kegiatan FGD yang dilaksanakan di kantor kelurahan desa Towangsan merupakan tahap awal untuk memperkenalkan agenda ESD. Hasil FGD ini akan menjadi dasar bagi para pemangku kebijakan untuk merumuskan model dan strategi dalam upaya penguatan kapasitas masyarakat dalam mewujudkan pembangunan yang berkelanjutan.

\subsubsection{Pelatihan Education for Sustainable Debelopment (ESD) - Pancasila \\ a. Pelatihan tentang Nilai-Nilai ESD}

Pelatihan bertema "Implementasi Nilai-Nilai Pancasila dalam Tiga Aspek ESD" bertujuan untuk mengajak warga negara, terutama masyarakat dan khususnya Karang Taruna untuk memahami dan mengerti tentang kondisi dan keadaan desanya masing-masing. Pemahaman yang utuh tentang sejarah desa dan filosofi desa menjadi penting untuk meletakkan dasar dan prinsip pembangunan yang berkelanjutan. Selain itu, latar belakang diselenggarakannya pelatihan ini adalah untuk memberikan bekal dan pengetahuan dasar tentang teknik penulisan sejarah desa serta manajemen organisasi dan komunikasi massa agar menjadi bagian terpenting dalam proses komunikasi di desa.

Selain itu, pelatihan ini juga bertujuan untuk membangun dan mengarahkan organisasi karang taruna agar memiliki nilai-nilai dan dasar beroganisasi yang baik dan benar. Dengan adanya dasar nilai dan organisasi yang benar diharapkan masyarakat dan generasi muda, khususnya yang ada di Towangsan dapat memahami arti pentingnya desa untuk masa depan yang lebih baik. Pelatihan ini diselenggarakan atas kerja sama Karang Taruna Sekarwono dan Sanggar Lare Mentes.

\section{b. Deskripsi Pelatihan}

Pelatihan yang membahas implementasi pendidikan untuk pembangunan yang berkelanjutan ini didasarkan pada konsepsi dasar tentang perlunya generasi muda untuk mengerti dan memahami pentingnya nilai hidup bersama sejak dini, yakni untuk menyelamatkan masa depan umat manusia dari ancaman kepunahan dan kehancuran karena persoalan lingkungan serta kondisi sosial-budaya yang semakin jauh dari keberadaban.

Kegiatan ini menjadi bagian integral dan penting dalam membangun kesadaran masyarakat untuk mengerti dan memahami dasar-dasar dan prinsip hidup bersama. Pelatihan ini mencoba mengelaborasi makna dan pengertian kehidupan yang berkelanjutan melalui bentuk pembangunan untuk semua orang. Dalam pelatihan ini peserta yang hadir berjumlah 21 orang.

Kegiatan ini melibatkan komunitas generasi muda, yaitu anggota dan pengurus karang taruna dan sanggar Lare Mentes. Pelatihan ini menghadirkan narasumber dari bidang sejarah dan psikologi. Pada aspek sejarah, para peserta diberikan materi tentang teknik dan strategi dalam menulis sejarah desa dan kampung. Pelatihan ini memberikan bekal kepada pengurus dan pengelola karang taruna untuk memahami sejarah desanya sehingga dapat merumuskan 
kebijakan pembangunan yang baik bagi desanya tersebut. Adapun di bidang psikologi, peserta diberikan bekal untuk berkomunikasi dengan baik dalam berorganisasi.

Berdasarkan hasil pelatihan diketahui bahwa partisipasi warga, terutama Karang Taruna Sekarwono untuk membuat dan mengembangkan desa cukup tinggi. Hal ini terlihat dari antusiasme generasi muda untuk ikut membangun desa. Fase observasi partisipatoris di Desa Towangsan menunjukkan bahwa Desa Towangsan memiliki potensi untuk dikembangkan, terutama perihal memperkuat dan menumbuhkan kesadaran masyarakat untuk mencintai desa dan melestarikan lingkungannya. Lingkungan yang masih asri dan pemandangan yang indah dengan udara yang sejuk akan menjadi modal alam yang penting bagi Desa Towangsan dalam membangun desa yang lebih berkelanjutan.

Berdirinya Pusat Inovasi dan Pengembangan ESD-Pancasila dapat menjadi media yang efektif dan efesien untuk membangun kemitraan strategis bagi desa, pemerintah, pemangku kepentingan, masyarakat, dan perguruan tinggi serta bersinergi dalam membangun desa dengan berbasiskan pada tiga aspek, yaitu lingkungan yang berkelanjutan, sosial-budaya yang berkelanjutan, dan ekonomi yang berkelanjutan. Modal sosial-budaya, seperti sanggar seni dan budaya untuk generasi muda, Karang Taruna Sekarwono, dan Gebyok Kebangsaan dapat menjadi ruang dialog dan berbagi untuk memecahkan masalah bersama dan mengembangkan desa.

\subsubsection{Workshop Education for Sustainable Development (ESD) Berbasis Nilai-Nilai Pancasila}

a. Term of Reference (TOR) Workshop

Workshop merupakan kegiatan untuk memberikan bekal pengatahuan dan skills terkait dengan masalah tertentu atau kegiatan tertentu. Workshop tentang pengembangan pusat inovasi dan pengembangan pendidikan untuk pembangunan yang berkelanjutan berdasarkan nilai-nilai Pancasila berbasis masyarakat di Desa Towangsan, Gantiwarno, Klaten Jateng. Workshop ini dilaksanakan sebagai upaya untuk memperkenalkan dan mensosialisasikan persoalan kebangsaan dan persoalan desa yang terjadi saat ini dengan merujuk pada tiga aspek, yaitu lingkungan, sosial-budaya, dan ekonomi.

Pemikiran tentang pembangunan desa yang berkelanjutan menjadi penting dengan adanya berbagai komunitas yang muncul dan berkembang. Komunitas menjadi salah satu wadah dan media untuk membangun masyarakat. Komunitas yang ada di Desa Towangsan, yakni Sanggar Lare Mentes, Karang Taruna Sekarwono, atau komunitas lain yang memiliki komitmen akan membangun desa yang lebih baik, berkelanjutan, memiliki nilai-nilai kebangsaan, dan berjati diri Pancasila perlu diberikan ruang seluas-luasnya untuk berekspresi di masyarakat.

Selanjutnya, workshop ini menghadirkan beberapa narasumber, yakni tokoh masyarakat di Desa Pancasila, Gowongan Kidul Yogyakarta, Bapak Harry Cahya dan Bapak Ben Senang Galus, S.H. dari Dikspora DIY. Kedua narasumber tersebut membahas aspek filosofi dan makna pendidikan untuk pembangunan yang berkelanjutan. Peserta yang hadir dalam workshop ini berjumlah dua puluh orang. Dalam kegiatan ini peserta mendapatkan materi yang lebih konkret tentang teknik mempraktikkan paradigma pendidikan untuk berkelanjutan yang berdasarkan Pancasila. Selain itu, peserta mendapatkan pengetahuan baru dan motivasi 
untuk menciptakan dan mengembangkan usaha baru, seperti membuat rencana usaha di desa berupa usaha pengembangan minuman lokal (kopi khas Mentes area Jawa Tengah).

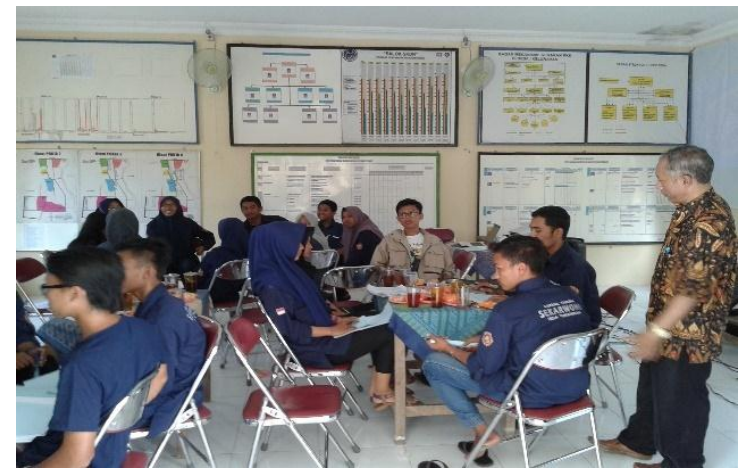

Sumber: Data primer diolah (2017)

Gambar 1. Suasana Workshop di Kelurahan Towangsan

\subsubsection{Pembuatan Desain/Logo dan Video Profil tentang Desa Towangsan.}

Pembuatan desain/logo Pusat Inovasi dan Pengembangan ESD- Pancasila Berbasis Komunitas di Desa Towangsan Gantiwarno merupakan upaya untuk menumbuhkan dan menggerakkan semangat generasi muda serta perangkat desa tentang pentingnya kesadaran membangun masyarakat yang berdasarkan pada tiga aspek, yaitu lingkungan berkelanjutan, sosial-budaya yang berkelanjutan, dan ekonomi yang berkelanjutan. Gambar 2. merupakan desain atau logo Pusat Inovasi dan Pengembangan ESD-Pancasila Berbasis Komunitas di Desa Towangsan, Gantiwarno, Klaten.

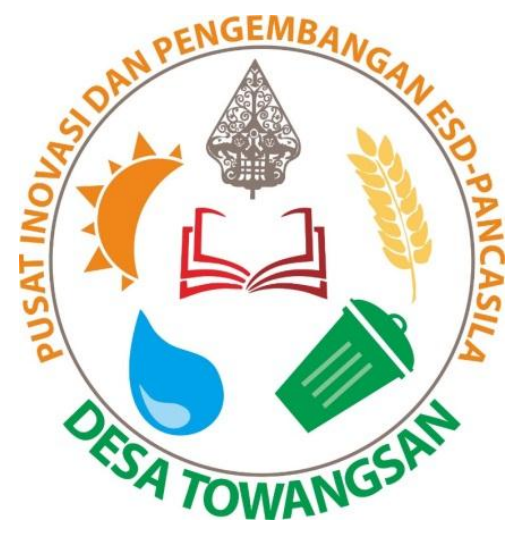

Sumber: Data primer diolah (2017)

Gambar 2. Logo Pusat Inovasi dan Pengembangan ESD-Pancasila

Tulisan "Pusat Inovasi dan Pengembangan ESD-Pancasila" merupakan dasar berpijak untuk memberikan wadah dan tempat bagi masyarakat untuk menyalurkan aspirasi inovatif dan kreatif yang digerakkan oleh Karang Taruna Sekarwono. Pusat Inovasi ini merupakan wadah untuk berdialog, mendokumentasikan, dan membuat solusi yang dapat dirasakan oleh masyarakat melalui kegiatan pendokumentasian, perumusan program kegiatan, dan penguatan kapasitas desa, terutama karang taruna agar selalu belajar bersama. 
Selanjutnya, gambar "matahari" melambangkan energi yang berarti setiap masyarakat memerlukan energi, baik energi terbaharukan maupun tidak terbaharukan. Bentuk energi yang nyata ialah energi listrik, energi matahari, dan energi yang dapat menghidupkan suasana desa. Dalam pelaksanaan pembangunan hendaknya masyarakat desa mempertimbangkan penggunaan energi yang ramah lingkungan dan energi yang berkelanjutan.

Kemudian, gambar "air" melambangkan air sebagai kebutuhan dasar manusia. Manusia tanpa air akan mengalami dehidrasi karena sekitar $70 \%$ tubuh manusia terdiri atas air. Lambang ini menandakan agar manusia sadar dan peduli akan kualitas dan keberadaan air di daerahnya. Air merupakan sumber kehidupan yang penting dan perlu dijaga kelestariannya supaya tidak tercemar.

Lalu, gambar "tempat sampah" melambangkan pentingnya menjaga kebersihan dan kelestarian lingkungan. Oleh karena itu, masyarakat perlu menyadari cara membuang sampah yang baik dan benar serta mengelolanya menjadi bahan yang bermanfaat. Menjaga kebersihan lingkungan dan kesehatan masyarakat merupakan upaya penting yang harus dilakukan agar desa tetap lestari dan berkelanjutan.

Seterusnya, gambar "padi" melambangkan masyarakat yang memerlukan sumber pangan. Salah satu sumber pangan terpenting adalah beras. Oleh karena itu, menjaga kesuburan tanah dan menjaga keberlanjutan menanam padi harus terus dilakukan. Padi juga melambangkan kesejahteraan dan kemakmuran.

Sementara, gambar "buku" melambangkan sikap masyarakat yang harus selalu terbuka akan pengetahuan dan ilm u baru serta mau belajar tentang kearifan dan nilai-nilai yang telah ada di dalam masyarakat.

Terakhir gambar "gunungan wayang" melambangkan agar masyarakat tetap melestarikan kebudayaan dan nilai-nilai kearifan lokal yang ada. Wayang merupakan simbol salah satu kebudayaan yang dapat memberikan pesan moral dan pesan kebudayaan, yakni agar generasi muda sadar akan budaya dan nilai-nilai kearifan lokal dan tidak terpengaruh dengan budaya lain.

\section{SIMPULAN}

Tercapainya program hibah Implementasi ESD-Pancasila ini telah menyatukan dan memberdayakan masyarakat dalam aspek peningkatan kualitas dan kesadaran untuk peduli kepada desanya dengan tetap melestarikan kearifan lokal dan menjunjung nilai-nilai budaya. Terbentuknya media atau wadah yang bernama Pusat Inovasi dan Pengembangan ESDPancasila di Desa Towangsan.

Kegiatan pelatihan bersama yang melibatkan partisipasi aktif masyarakat di Desa Towangsan, terutama Karang Taruna Sekarwono dan Sanggar Lare Mentes dapat meningkatkan kesadaran dan kualitas masyarakat untuk berpartisipasi dan berkegiatan bersama. Masyarakat yang sebelumnya jarang bertemu dan berdiskusi menjadi semakin akrab melalui kegiatan ini. Selain itu, juga terdapat video profil Desa Towangsan. Dapat dikatakan bahwa, pelaksanaan kegiatan hibah Implementasi ESD-Pancasila telah membawa dampak positif di Desa Towangsan karena telah memotivasi masyarakat, terutama anak-anak muda yang tergabung dalam organisasi karang taruna untuk memiliki kepercayaan diri karena bisa bermitra dengan Universitas Gadjah Mada dalam membangun desanya. 


\section{DAFTAR PUSTAKA}

Amyyana, Paristiowati, M., \& Kurniadewi, F. (2017). Pirolisis Sederhana Limbah Plastik dan Implementasinya sebagai Sumber Belajar Berbasis Education For Sustainable Development (ESD) Pada Pembelajaran Kimia. JRPK: Jurnal Riset Pendidikan Kimia, Vol. 7, No. 1, 14-21.

Byun, W.J., Leicht, A., \& Heiss, J. (eds). (2018). Issues and Trends in Education for Sustainable Development. France: UNESCO.

Marthaliakirana, Irawati, \& Rohman, F.

(2018). Education for Sustainable Development (ESD) Melalui Pemahaman Masyarakat untuk Mengurangi Sampah Popok Sekali Pakai dengan Menggunakan Popok Reuse. Jurnal Florea, Vol.5, No.1, 29-39.

Segara, N., B. (2015). Education for

Sustainable Development (ESD) Sebuah Upaya Mewujudkan Kelestarian Lingkungan. SOSIO DIDAKTIKA: Social Science Education Journal, 2(1), 22-30. doi:10.15408/sd.v2i1.1349.

Sulistiyani, A.T \& Wulandari, Y. (2017). Proses Pemberdayaan Masyarakat Desa Sitimulyo, Kecamatan Piyungan, Kabupaten Bantul dalam Pembentukan Kelompok Pengelola Sampah Mandiri. Indonesian Journal of Community Engagement Vol. 02, No. 02, 146-162.

Zaenuri, Utomo Y., \& Juul.E. (2017). Habituation Model of Implementing Environmental Education in Elementary School. Universitas Negeri Semarang: Jurnal Pendidikan IPA Indonesia, Vol.6, No.2, 206-212. 